\title{
A case of multiple myeloma that healed completely after oral intake of 4-hydroxybenzaldehyde
}

\section{Kimihiko Okazaki* \\ Okazaki Medical Clinic, Ukyoku Kyoto, Japan}

\section{Introduction}

In 1985, Mutsuyuki Kochi [1,2] reported a novel anti-tumor agent after acquiring a Japanese Patent in 1969. According to his patent, 4-Hydroxybenzaldehyde is an anti-tumor agent without any sideeffects. My impression is that this medicine is capable of preventing carcinogenesis when used quantitatively sufficiently. In order to treat developed cancers, you ought to start giving your cancer patient a small dose of the stuff because, otherwise, the patient may suffer from a serious haemorrhage of the tumor caused by excessive necrosis. Therefore, lymphomas and leukaemia's can be treated more easily because these tumors have no blood vessels. Consequently, those who have these diseases receive considerably large dose of the medicine.

On the other hand, it appears that little is known about a safe and ensured method of prevention of carcinogenesis. As a matter of fact, discovery of a specific cancer drug has been reported as long as 33 years ago. Although the discoverer did not demonstrate the mechanism of action of the stuff, it is highly possible that the stuff inhibits activity of tyrosine kinase, which is the rate-limiting enzyme in the pass-way of carcinogenesis [3]. The basis of this argument is an enzymologically established concept that a chemical compound, of which structure is similar to that of the substrate of the enzyme, exhibits an inhibitory activity towards the enzyme. To be more convincing, the enzyme molecule accepts the inhibitor into its substrate site as an error. Both of tyrosine and benzaldehyde have benzene nucleus and carbonate radical in common.

As far as the reason why the discovery of the specific cancer drug has not been known widely is concerned, I can't tell anything since I'm not an oncologist.

\section{Case}

An older brother of a 63-year-old man(K.O.) visited the author's clinic on February 28, 2013. The visitor talked about his sick brother as follows: The patient repeated his costal bone fractures during the period from January 2012 to February 2012. In March 2012, he underwent a clinical examination, which revealed that processes spinalis of his 12th thoracic spinal bone was invaded by malignancy [1]. He had a renal insufficiency [2]. He had M-proteinemia. and in conclusion, he was diagnosed as Multiple Myeloma of Stage III-B [3]. These examinations were performed at The Iwata City General Hospital, where the patient was treated with Bortezomib plus Dexamethasone. As of January 10, 2013 , less than $5 \%$ of the patient's bone marrow was myeloma, which was $66 \%$ before the treatment. The blood IgG level, measured on the same day, was approximately $500 \mathrm{mg} / \mathrm{dl}$, which was $4900 \mathrm{mg} / \mathrm{dl}$ before the treatment. The blood beta- 2 micro-globulin, measured on the same day, was $1.7 \mathrm{mg} / \mathrm{dl}$, which was $4.3 \mathrm{mg} / \mathrm{dl}$ before the treatment.

I prescribed him with daily $500 \mathrm{mg}$ of 4 -Hydroxybenzaldehyde, dissolved in $100 \mathrm{ml}$ of mineral water for 60 -day-period. On the $61 \mathrm{st}$ day, I raised the daily dose to $750 \mathrm{mg}$ dissolved in $300 \mathrm{ml}$ of mineral water for 40 days. On the 41 st day, I raised the daily dose to $1 \mathrm{~g}$ of the medicine mixed with 9 -times as much starch for 40 days. Each $0.25 \mathrm{~g}$ of the medicine in the form of fine powder was packed after mixing with $2.25 \mathrm{~g}$ of starch powder with the aid of the packing machine. On the $41 \mathrm{st}$ day, I raised the daily dose to $1.5 \mathrm{~g}$ of the medicine mixed with 9-times as much starch for 20 days. On the 21 st day, I raised the daily dose to $2 \mathrm{~g}$ of the medicine mixed with 9-time as much starch for 40 days. On the 41 st day, I raised the daily dose to $3 \mathrm{~g}$ of the medicine mixed with 9-times as much starch for 40 days. On the 41 st day, I raised the daily dose to $4,5 \mathrm{~g}$ of the medicine mixed with 9 -times as much starch for 30 days. On the 31 st day, I raised the daily dose to $6 \mathrm{~g}$ of the medicine mixed with 9 -times as much starch for 30 days. On the 31 st day, I raised the daily dose to $7.5 \mathrm{~g}$ of the medicine mixed with 9-times as much starch for 605 days. At the end of May 2016, the patient voluntarily stopped taking the medicine presumably because of absence of subjective symptoms. As of April 13, 2018, he enjoys a healthy life.

\section{References}

1. Kochi M (1985) Antitumor Activity of a Benzaldehyde Derivative. CancerTreatment Reports 69: 533-537. [Crossref]

2. Kochi M (1969) Manufacturing Process of Anticancer Substance. Japanese Patent No. 560349.

3. Okada M, Nakagawa H (1989) A Protein Tyrosine Kinase Involved in Regulation of pp60 Function. J Biol Chem 264: 20886-20893. [Crossref]
Copyright: (C)2018 Okazaki K. This is an open-access article distributed under the terms of the Creative Commons Attribution License, which permits unrestricted use, distribution, and reproduction in any medium, provided the original author and source are credited.
Correspondence to: Kimihiko Okazaki, Okazaki Medical Clinic, Ukyoku Kyoto, Japan

Received: April 02, 2018; Accepted: April 19, 2018; Published: April 23, 2018 